\title{
ケーブルの面外不安定振動
}

\section{OUT-OF-PLANE VIBRATIONS OF SUSPENDED CABLES UNDER INPLANE FORCING}

\author{
高橋和 雄*・田川賢**・佐藤 秀 雄***
}

By Kazuo TAKAHASHI, Masaru TAGA WA and Hideo SATO

\begin{abstract}
It is known that out-of-plane vibrations of suspended cables are observed under inplane forcing. This fact is caused by the geometrical nonlinearity of cables. Singledegree-of-freedom approach for this problem was used in the preceding work. In the present work, out-of-plane vibrations of cables are studied by using multiple-degree-offreedom approach because cables are continuous system. Nonlinear inplane responses and corresponding out-of-plane vibrations are analyzed by the harmonic balance method. Unstable regions where out-of-plane vibrations occur are obtained. The results of numerical examples show that unstable regions of out-of-plane vibrations whose modal shapes are similar to those of inplane modal shapes are wide and that simple parametric resonances are signficant compared with combination resonances.
\end{abstract}

\section{1. まえがき}

ケーブルに面内外力が作用すると，特定の振動数領域 で面外振動が生ずることが知られている。この問題は ケーブルの幾何学的非線形性に基づく非線形振動に起因 するものである. 本題に関する研究については山口ら ${ }^{1121}$ によって面内・面外とも 1 自由度系とみなした解析が行 われ, また, 面内加振による面内・面外連成振動実験結 果が報告されている.これらの研究によってケーブルの 面外不安定振動は弦と異なって主不安定領域が存在する ことおよびサグ比, 傾斜角の形状パラメーターによって その特性が異なるこしなどが明らかにされている.

ケーブルは無限の自由度を有するために多自由度とし ての定量的な取扱いが必要である. しかし, 面内非線形 応答を評価のうえ，面外不安定に関する連立の Hill の 方程式の解をすべて求めることが困難なこともあって多 自由度系としての取扱いは見受けられないようである. そこで, 本研究はケーブルの面内加振による面外係数励 振振動を多自由度係として取り扱うものである。面内非線

* 正会員 工修 長崎大学助教授 工学部土木工学科 ( ₹852 長崎市文教町 1 - 14)

** 正会員 (株) 日本構造橋梁研究所

*** 大日本コンサルタント(株)
形応答および面外不安定振動の評価には調和バランス 法 $^{31,4)}$ を用いるものである. 本法によれば 1 自由度系よ しての取扱いでは追従が無理なケーブルの面内非線形応 答を評価したうえで, 単一の面外振動形をもつ単純共振 および 2 個の面外振動形をもつ結合共振を体系的に明ら かにすることが可能である，本ノ一トはまず，解法の展 開ののち, ケーブルの面外振動の性質を明らかにし, 次 いで面外不安定振動の種類および広さ，これらに及ぼす ケーブルの形状の影響を明らかにするものである.

なお, 本ノートの面外不安定振動解析は面外振動が生 ずる分岐点近傍の挙動のみを明らかにするものである.

この取扱いは文献 3)の 5.（2）の面外非線形分岐応答解 析において面外の非線形項を無視した場合に一-致する. このような取扱いによって, 文献 5)のケーブルの運動 方程式は面内と面外成分に分離され，それぞれ独立に解 析することが可能である.

\section{2. 解 法}

\section{（1）面内非線形必答解析}

面内加振を受けるケーブルの面内非線形運動方程式は 次の上うに与えられる5 .

$$
L_{1}(u, v)=\frac{\partial^{2} u}{\partial t^{2}}-\frac{\partial}{\partial s_{e}}\left\{\left(C_{0}^{2} \frac{1}{x_{e}^{\prime}}+C_{1}^{2} x_{e}^{\prime 2}\right) \frac{\partial u}{\partial s_{e}}\right.
$$




$$
\begin{aligned}
& \left.+C_{1}^{2} x_{e}^{\prime} y_{e}^{\prime}-\frac{\partial v}{\partial s_{e}}\right\} \\
& -C_{1}^{2} \frac{\partial}{\partial s_{e}}\left[\left(x_{e}^{\prime} \frac{\partial u}{\partial s_{e}}+y_{e}^{\prime} \frac{\partial v}{\partial s_{e}}\right) \frac{\partial u}{\partial s_{e}}\right. \\
& \left.+\frac{1}{2}\left\{\left(\frac{\partial u}{\partial s_{e}}\right)^{2}+\left(\frac{\partial v}{\partial s_{e}}\right)^{2}\right\}\left(x_{e}^{\prime}+\frac{\partial u}{\partial s_{e}}\right)\right] \\
& -\frac{p_{x} \cos \Omega t}{\rho_{0}}=0 \\
& L_{2}(u, v)=\frac{\partial^{2} v}{\partial t^{2}}-\frac{\partial}{\partial s_{e}}\left\{\left(C_{0}^{2} \frac{1}{x_{0}^{\prime}}+C_{1}^{2} y_{e}^{\prime 2}\right) \frac{\partial v}{\partial s_{e}}\right. \\
& +C_{1}^{2} x_{e}^{\prime} y_{e}^{\prime} \frac{\partial u}{\partial s_{e}} \\
& -C_{1}^{2} \frac{\partial}{\partial s_{e}}\left[\left(x_{e}^{\prime} \frac{\partial v}{\partial s_{e}}+y_{e}^{\prime} \frac{\partial v}{\partial s_{e}}\right) \frac{\partial v}{\partial s_{e}}\right. \\
& \left.+\frac{1}{2}\left\{\left(\frac{\partial u}{\partial s_{e}}\right)^{2}+\left(\frac{\partial v}{\partial s_{e}}\right)^{2}\right\}\left(y_{e}^{\prime}+\frac{\partial v}{\partial s_{e}}\right)\right] \\
& -\frac{p_{y} \cos \Omega t}{\rho_{0}}=0
\end{aligned}
$$

ここに, $u, v$ : 面内水平, 鉛直変位, $t$ : 時間, その他 の記号は文献 5$)$ 参照.

文献 3)の式( 4 ),（5)，（6），（7）の面内の項のみ を取り出せば, 式( 1 ), （2)の面内非線形応答が得られ る. 面外振動解析に必要な式のみを示せば次のとおりで ある。

$$
\left.\begin{array}{l}
u=l \sum_{i=1} P_{i}(t) U_{i}\left(s_{e}\right) \\
v=l \sum_{i=1} P_{i}(t) V_{i}\left(s_{e}\right)
\end{array}\right\}
$$

ここに, $l$ : 支点間水平距離, $U_{i}, V_{i}$ : 固有振動形

$$
P_{i}(t)=\sum_{m=0} a_{m}^{i} \cos m \omega \tau
$$

ここに, $\tau=\omega_{1} t, \omega=\Omega / \omega, \omega_{1}$ : 弦の 1 次の固有円振動数

\section{（2）面外係数励振振動}

面外振動の非線形項を無視した自由振動の運動方程式 は次のように表わされる.

$$
\begin{aligned}
& \frac{\partial^{2} w}{\partial t^{2}}-\frac{\partial}{\partial s_{e}}\left(C_{0}^{2} \frac{1}{x_{e}^{\prime}} \frac{\partial w}{\partial s_{e}}\right)-C_{1}^{2} \frac{\partial}{\partial s_{e}}\left[\left(x_{e}^{\prime} \frac{\partial u}{\partial s_{2}}+y_{e}^{\prime} \frac{\partial v}{\partial s_{e}}\right)\right. \\
&\left.\frac{\partial w}{\partial s_{e}}+\frac{1}{2}\left\{\left(\frac{\partial u}{\partial s_{e}}\right)^{2}+\left(\frac{\partial v}{\partial s_{e}}\right)^{2}\right\} \frac{\partial w}{\partial s_{e}}\right]=0 \cdots \cdots \cdots \cdots(5) \\
& \text { ここに, } w \text { : 面外変位 }
\end{aligned}
$$

式( 5 )の解を次のように仮定する.

$$
w=\sum_{i=1} T_{i}(t) W_{i}\left(s_{e}\right)
$$

ここに, $T_{i}(t)$ : 未知の時間関数, $W_{i}\left(s_{e}\right)$ : 面外固有振 動形

式( 5 )に式( 3 )，（6)を代入し，さらに式( 4 )におい て $m=3$ まで採用した場合 ${ }^{31}$ の Galerkin 法による結果は 次式となる.

$$
\left.\left.\left[A_{1}\right]\right\} \ddot{T}\right\}+\left[A_{k}\right]\{T\}+k^{2}\left(\left[D_{p}^{0}\right]+\left[D_{\rho}^{1}\right] \cos \omega \tau\right.
$$$$
\left.+\left[D_{\rho}^{2}\right] \cos 2 \omega \tau+\left[D_{p}^{3}\right] \cos 3 \omega \tau\right)\{T\}=\{0\}
$$

ここに, $\left[A_{l}\right],\left[A_{k}\right]$, 係数行列, $\left[D_{\rho}^{0}\right]$ : 面内非線形応答に
よる付加剛性行列, $\left[D_{\rho}^{i}\right], i=1,2,3$ : 係数励振振動の幅 種類を決定する行列, $\{T\}=\left[T_{1}, T_{2} \cdots \cdots\right]^{T}$

式( 7 )は連立の Hill の方程式である. 式( 7 )の解を 次のように仮定する4).

$$
\{T\}=e^{\lambda \tau}\left\{\frac{1}{2} \boldsymbol{b}_{0}+\sum_{m=1}\left(\boldsymbol{a}_{m} \sin m \omega \tau+\boldsymbol{b}_{m} \cos m \omega \tau\right)\right\}
$$

ここに, $\lambda$ : 未知定数, $\boldsymbol{b}_{0}, \boldsymbol{a}_{m}, \boldsymbol{b}_{m}:$ 末知のベクトル

上式を式( 7 )に代入して, 再び調和バランス法を適用 すれば，次のような同次方程式が得られる.

$[D]\{X\}=\{0\} \cdots$

こに, $[D]$ : 係数行列, $\{X\}: \boldsymbol{b}_{0}, \boldsymbol{b}_{m}, \boldsymbol{a}_{m}$ からなる列べクト ル

上式に含まれる入は文献 4)に示す方法を用いて固有 值問題に変換でき, ケーブルの面外振動の安定, 不安定 が直接判定される.

\section{3. ケーブルの面外不安定振動の性質}

式( 7 )の微分方程式は次の振動数比 $\omega$ の近傍で不安 定領域をもつ.

$$
\begin{aligned}
{\left[D_{\rho}^{1}\right]: \omega } & =2 \omega_{i}^{0} / \bar{i}, \\
\omega & =\left(\omega_{i}^{0} \pm \omega_{j}^{0}\right) / \bar{i}, \quad \bar{i}=1,2, \cdots \\
{\left[D_{\rho}^{2}\right]: \omega } & =2 \omega_{i}^{0} / \bar{j}, \\
\omega & =\left(\omega_{i}^{0} \pm \omega_{j}^{0}\right) / \bar{j}, \quad \bar{j}=2,4, \cdots \\
{\left[D_{\rho}^{3}\right]: \omega } & =2 \omega_{i}^{0} / \bar{l}, \\
\omega & =\left(\omega_{i}^{0} \pm \omega_{j}^{0}\right) / \bar{l}, \quad \bar{l}=3,6, \cdots
\end{aligned}
$$

ここに, $\omega_{i}^{0}:$ 無次元面外 $i$ 次固有振動数

$2 \omega_{i}^{0} / \bar{i}$ のように単一の振動数をもつ不安定振動を単純 共振といい, $\left(\omega_{i}^{0} \pm \omega_{j}^{0}\right) / \bar{i}$ のように 2 つ振動数からなる 不安定振動を結合共振 (+: 和形, 一 : 差形) という. $\bar{i}=1$ が主不安定領域で, $\bar{i} \geq 2$ が副不安定領域である. したがって, $\left[D_{p}^{2}\right]$ 行列から得られる不安定領域には奇 数次の不安定領域は存在しない. また, $\left[D_{\rho}^{3}\right]$ から得ら れる不安定領域には主, 第 2 不安定領域は存在しない. 結合共振は多自由度としての取扱いではじめて得られる ものである.

式(10)で示した不安定振動のうち，いずれの不安定領 域が必要であるかは, 係数行列 $\left[D_{p}^{i}\right]$ の要素構成, すな わちケーブルの形状, 加振状態および面内非線形応答の 振幅によって定まる.ケーブルの場合に $\left[D_{p}^{i}\right]$ の対角線 要素 $d_{j j}^{i} \neq 0$ であるから, 必ず単純共振が存在する. また, 対称行列 $d_{j l}^{i}=d_{l j}^{i}$ であるから， $d_{j l}^{i}$ と $d_{l j}^{i}$ は同符号とな る.したがって, 結合共振は和形のみが存在し, 差形は 存在しない.

\section{4. 不安定領域の決定法}

不安定領域の作成にあたっては, 荷重強度 $p_{n}$ を一定 
に保って面内非線形応答を求め, その面内応答のもとに おける面外振動の安定性を吟味する. 次に荷重強度 $p_{n}$ を変化させて, 同様な操作を繰り返せば不安定領域が構 成される.この不安定領域には Fig. 1 に示すように Type (A)と Type(B)の 2 個がある. Type (A)は通常の 不安定領域で応答曲線上に左側と右側が存在する場合で ある.これに対して Type(B)は左側の境界線のみが存 在し, 右側の境界点は応答曲線上に存在しない.しかし, この場合外力の荷重強度 $p_{n}$ が零である自由振動の応答 曲線（backbone curve）より右側には応答が存在しな いために，この曲線によって領域の右側が規定される. この Type(B)の不安定領域は主共振近傍にのみ生するる.

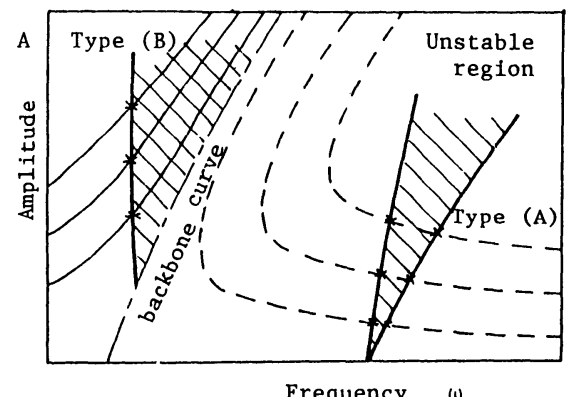

Fig. 1 Construction of unstable regions.

\section{5. ケーブルの面外不安定領域}

Fig. 2 および 3 に水平ケーブル $(k=30, \gamma=0.1)$ の面内 対称および逆対称加振の場合の面内非線形応答と面外不 安定領域を示す．図中において横軸は外力の加振円振動 数を対応する弦の 1 次固有円振動数で無次元化した振動
数比 $\omega$ で, 縦軸はケーブルの中央点（対称加振の場合）, もしくは $3 / 10$ 点（逆対称加振の場合）における振幅を スパン長 $l$ で無次元化した振幅比 $A$ である ${ }^{3 !}$. 図中の実 線は特定の荷重強度のもとでの外力と同位相の面内非線 形応答を，また破線は外力と逆位相の面内非線形応答を 表わしたものである．応答曲線上のய世（または开）の 記号は，応答曲線が鉛值接線をもつ位置を示すもので， 斜線部内の応答は不安定な（実現しない）振幅である. 肉太の実線および破線が安定な振幅である。なお，応答 曲線に付した記号 $a_{j}^{n}$ は, 面外 $n$ 次振動の $j$ 倍 $(j=1$ の 場合：主調波, $j \geqq 2$ の場合：高調波）振動が卓越する ことを意味する.

以上の安定な面内非線形応答のもとに生ずる面外不安 定領域が図中の斜線部である．右上りの斜線部が単純共 振の不安定領域に対応し, 右下りの斜線部が結合共振の 不安定領域に対応する. 不安定領域に示した記号 $2 \omega_{i}^{0} / \bar{i}$ は面外 $i$ 次振動の単純共振の $\bar{i}$ 番目の不安定領域を示 す. また, 記号 $\left(\omega_{i}^{0}+\omega_{j}^{0}\right) / \bar{i}$ は面外 $i$ 次と $j$ 次振動の結 合共振の $\bar{i}$ 番目の不安定領域を示す.

Fig. 2 の面内対称加振の場合には, ケーブルの 2 次お よび 3 次の非線形項が応答に寄与するために, 式 ( 9 )の $\left[D_{\rho}^{i}\right]$ 行列がすべて零行列とならない.このために，主 および副の不安定領域が存在する. 水平ケーブルの場合 の結合共振については, 面外振動形が対称-対称もしく は逆対称-逆対称の組合せのみが存在する. 図のように 不安定領域の幅は単純共振の方が結合共振よりも広い。 特に $\omega=3.5$ 付近に生ずる面外 3 次振動の副不安定領域 $\left(\omega_{3}^{0}\right)$ が最も広いといえる.このときのケーブルの面内非 線形応答 $\left(\omega_{1}^{i}\right)$ と面外不安定振動 $\left(\omega_{3}^{0}\right)$ の振動形はよく似 ている ${ }^{5}$. 不安定領域の幅が広いほ亡゙固有値 $\lambda$ の実数部

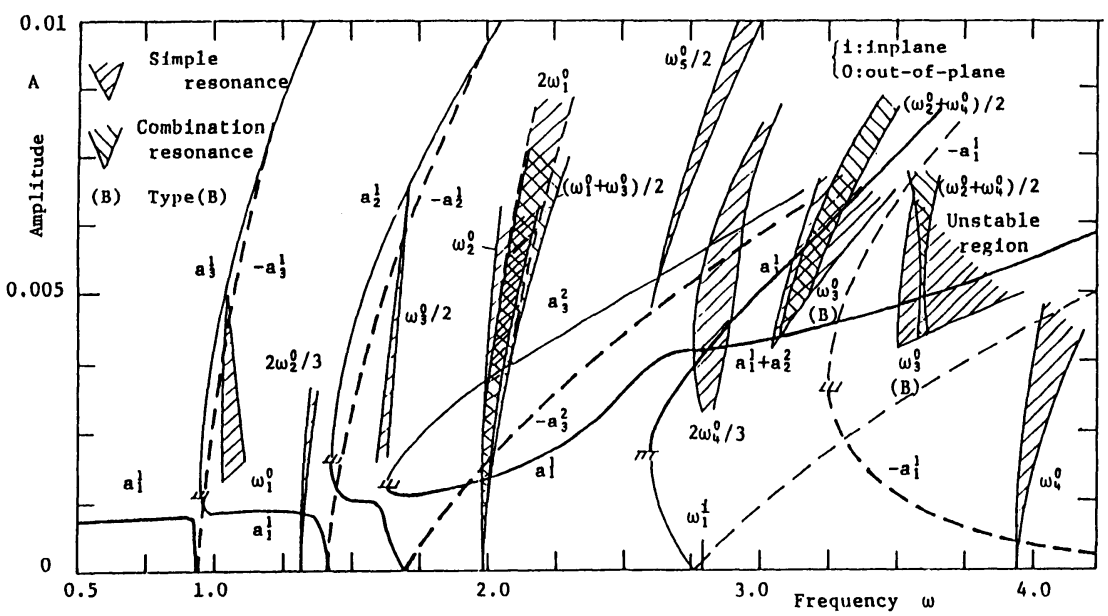

Fig. 2 Unstable regions of out-of-plane vibrations of a cable with $k=30, \gamma=0.1$ and $\theta=0^{\circ}$ under symmetric forcing. 


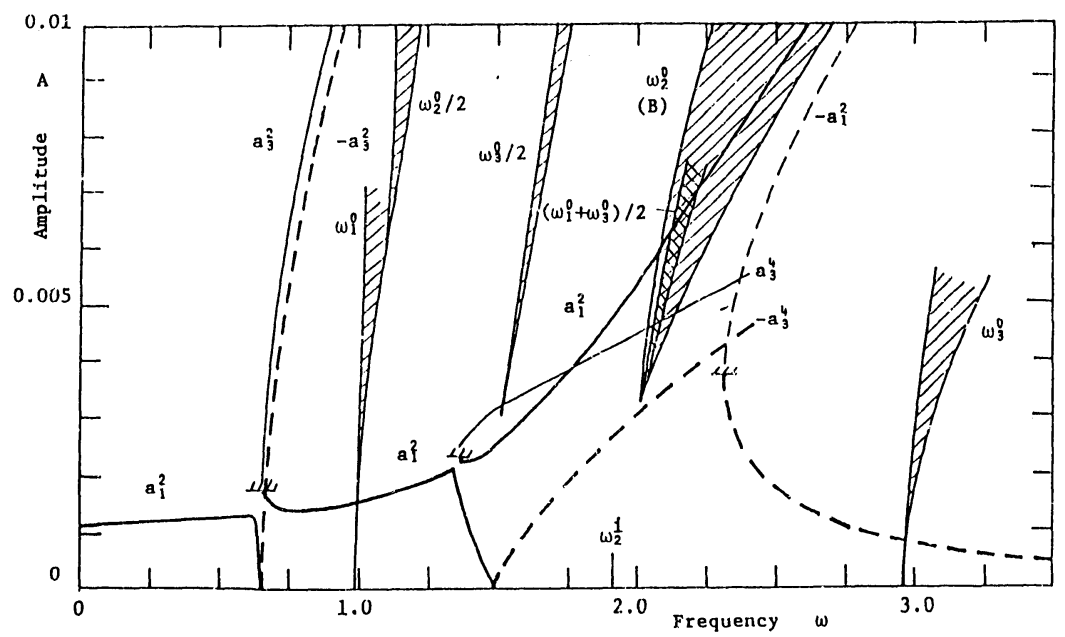

Fig. 3 Unstable regions of out-of-plane vibrations of a cable with $k=30, \gamma=0.1$ and $\theta=0^{\circ}$ under anti-symmetric forcing.

の値が大きく，強い面内・面外連成振動が生じる。

逆に Fig. 3 の面内逆対称加振の場合にはケーブルの非 線形項に 3 次の項のみが含まれるために，弦と同様に ケーブルの応答には主共振のほかに奇数次の高調波応答 のみが含まれる．この場合，係数行列 $\left[D_{p}^{1}\right],\left[D_{p}^{3}\right]$ がゼロ 行列となるために，主不安定領域をはじめ奇数次の不安 定領域は存在しない(このことはすでに文献1)に示さ れている).したがって，不安定領域の種類は対称加振 よりも少ない。本ケースにおいても， $\omega=2.0$ 付近の面 内 2 次逆対称振動 $\left(\omega_{2}^{i}\right) \sigma$ 主共振近傍の面外 2 次振動 $\left(\omega_{2}^{0}\right)$ の副不安定領域が最も広い.

次に傾斜ケーブルの場合には応答に 2 次および 3 次の 非線形項が同時に含まれるために，水平ケーブルの対称 加振による面内非線形応答上同様な忘答特性之面外不安 定振動の種類をもつ. また，茾比 $\gamma=0.0$ の弦の場合 には対称加振・逆対称加振の区別なくケーブルの面内逆 対称加振亡同し種類の不安定領域をもつ。

Fig. 2 および 3 に示したように，面内忘答の主共振近 傍で面内振動形亡よく似た面外振動形をもつ単純共振の 副不安定領域が最も広い。不安定領域の広さは応答曲線 の傾きが大きい場合，すなわち，非線形性が大きい場合 に広くなる。文献 3)の図一3に示した面内非線形自由振 動の計算結果によれば, サグ比 $\gamma=0.1$ の水平ケーブル の対称振動の非線形性が最も大きい。したがって，Fig. 2 の $\omega=3.5$ 付近の面外不安定領域がケーブルにおいて 最も広いことが予想される. 逆に $\gamma=0.02 \sim 0.05$ 付近の ケーブルでは非線形性が小さいために，弦よりも不安定 領域は狭くなることが予想される。

\section{6. ま と め}

本ノ一トは面内加振を受けるケーブルの面外振動を多 自由度系の係数励振振動問題として定式化し，ケーブル の面外不安定領域を示したものである．得られた知見を まとめると

（1）ケーブルの面外不安定領域には単一の面外振動 形をも一単純共振のほかに，2 個の面外振動形をもつ和 形の結合共振の 2 種類が存在する.

（2）面外不安定領域の幅は一般に単純共振の方が結 合共振よりも㕕い。特に面内の主共振近傍で面内振動形 と似た面外振動形をもつ不安定領域の幅が最も広い.

（３）ケーブルの面外不安定領域は面内非線形性が大 きい場合に広くなる。

本研究の数值計算には金近伸広氏（現山口県上地開発公社） の協力を得たことを付記する。

\section{参 考 文 献}

1）山口・宮田・伊藤：ケーブル系の非線形応答における-・ 挙動, 第 24 回構造工学シンポジウム論文集, pp. $51 〜 61$, 1978.

2）山口・清水・伊藤：ケーブルの非線形動的忘答に関する 実験的研究, 土木学会第 36 回年次学術講演会講演概要集, 第 1 部, pp. $371 \sim 372$, 昭和 56 年 10 月.

3）高橋・藤本・村中・田川：調和バランス法によるケーブ ルの非線形振動解析, 土木学会論文報告集, 第 338 号, pp. $57 \sim 68,1983$.

4) Takahashi, K. : Instability of Dynamic Systems with Non-uniform Damping, Journal of Sound and Vibration. Vol. 85, pp. 257 - 262, 1982.

5）山口・伊藤：単一ケーブルの三次元非線形自由振動，上 木学会論文報告集, 第 286 号, pp. $29 \sim 36,1979$.

(1984 年 1 月 11 日・受付) 